\title{
Effect of MgO powder addition to alkali and alkaline-earth borosilicate glass paste on the acid durability and peel adhesion characteristics of Ag conductors formed with the glass paste
}

\author{
Yusuke TACHIBANA ${ }^{1,2, \dagger}$, Akifumi MATSUDA ${ }^{2}$ and Mamoru YOSHIMOTO2 \\ ${ }^{1}$ DuPont Electronics Center, DuPont Electronic Materials, K. K., Kawasaki 213-0012, Japan \\ ${ }^{2}$ Department of Materials Science and Engineering, Tokyo Institute of Technology, Yokohama 226-8502, Japan
}

\begin{abstract}
In this study, we investigated the influence of the addition of $\mathrm{MgO}$ powder to the alkali and alkaline-earth borosilicate (AEB) glass paste on acid durability and peel adhesion characteristics of Ag conductors formed on the alumina substrate with the AEB glass paste. It was determined that the addition of the MgO powder to the AEB glass paste promoted crystal precipitation during the firing process of the printed AEB glass thick-film on the substrate at $850{ }^{\circ} \mathrm{C}$. By characterizing the acid corrosion behavior in $\mathrm{a}_{2} \mathrm{SO}_{4}$ aq., the weight loss after immersion for the micro-crystallized AEB glass thick-film with the added MgO powder was reduced by approximately half compared with that of the AEB glass thick-film without the MgO powder. In addition, no cracks were observed on the film surface of the micro-crystallized AEB glass, whereas cracks appeared on the film surface of the non-crystallized AEB glass after the acid corrosion treatment. It is thought that microcrystallization induced by the addition of $\mathrm{MgO}$ powder to the glass paste during the firing process is partly involved in improving the acid resistance of the AEB glass thick-film. During the peel adhesion test of the Ag conductor on the alumina substrate in $_{2} \mathrm{SO}_{4}$ aq., the Ag conductor formed with the $\mathrm{MgO}$ powder-added AEB glass paste exhibited small deterioration of peel adhesion in comparison to the Ag conductor formed using the AEB glass paste without the MgO powder. These results suggest that the correlation between the improved acid durability and peel adhesion characteristics of the Ag conductor formed with the MgO powder-added AEB glass paste was related to the micro-crystallization of the AEB glass induced by the addition of $\mathrm{MgO}$ powder to the thick-film pastes during the annealing process at $850^{\circ} \mathrm{C}$.

(O2020 The Ceramic Society of Japan. All rights reserved.
\end{abstract}

Key-words : Borosilicate glass, Glass paste, Chemical durability, Crystallization, Acid corrosion, Ag conductor paste, Thick-film, Peel adhesion

[Received August 9, 2019; Accepted January 7, 2020]

\section{Introduction}

Over the past 50 years, thick film pastes, which are produced by mixing and dispersing glass frits, metal powders, and/or inorganic materials with an organic vehicle, have been used as thick-film conductors, resistors, and dielectrics for electric circuits on ceramic substrates [e.g., alumina $\left(\mathrm{Al}_{2} \mathrm{O}_{3}\right)$ ] using the screen printing technique. It is clear that thick-film pastes have considerably contributed to the development of hybrid microcircuits and chip components in many segments of the electronics industry: medical, telecommunications, automotive, aerospace, and consumer electronics. ${ }^{1)}$

Glasses in thick-film conductors promote sintering of metal powders (e.g., Ag) during the firing and binding of the metal film to the substrate. ${ }^{1-3)}$ Therefore, low-melting glasses are suitable for thick-film conductors, and lead

Corresponding author: Y. Tachibana; E-mail: tachibana.y. ag@m.titech.ac.jp borosilicate glasses have been extensively used. ${ }^{1), 4)}$ Lead lowers the melting temperature of glasses and facilitates melting of various metal oxides into glasses in a wide glass formation range. ${ }^{5)}$ Consequently, lead borosilicate glasses are useful for designing metal-containing thick-film conductors with low resistivity and strong adhesion on ceramic substrates with high reliability. However, environmental regulations, such as the Waste Electrical and Electronic Equipment Directive and Restriction of Hazardous Substances Directive from 2003, banned the use of lead for many applications, the scope of which is continuously expanding.

It is known that $\mathrm{Bi}_{2} \mathrm{O}_{3}$-based glasses, phosphate glasses, and borosilicate glasses containing $\mathrm{B}_{2} \mathrm{O}_{3}$ and/or alkali a lot are available as $\mathrm{Pb}$-free low-melting glasses. ${ }^{6)-8)} \mathrm{In}$ addition, $\mathrm{ZnO}, \mathrm{SnO}$ and/or fluorides decrease the melting temperature of glasses. ${ }^{6}$ ) Despite these advances, high chemical durability is a challenging for most low-melting $\mathrm{Pb}$-free glasses. For instance, there are many studies on corrosion mechanisms of borosilicate glasses. Leaching 
occurs due to the replacement of network-modifying constituent ions (e.g., alkali) with $\mathrm{H}^{+}\left(\mathrm{H}_{3} \mathrm{O}^{+}\right)$from the solution, and solutions containing these protonated species enhance such reaction. ${ }^{9)-11)}$ Glass network dissolution occurs due to the nucleophilic attack of $\mathrm{OH}^{-}$on the silicate network under alkali conditions. ${ }^{9)}{ }^{-11)}$ On the other hand, the strong chemical durability of crystallized glasses has received considerable attention. ${ }^{12), 13)}$

Although the microstructure analysis of thick-film conductors glass-bonded onto $\mathrm{Al}_{2} \mathrm{O}_{3}$ substrates and the effect of the firing conditions and $\mathrm{Al}_{2} \mathrm{O}_{3}$ substrate characteristics (e.g., composition and surface texture) on adhesion behavior have been investigated, there are few studies on the chemical durability of thick-film conductors under acidic conditions. ${ }^{1-4), 14), 15)}$ Better understanding of the acid corrosion behavior of glass in thick films would facilitate the designing of thick-film conductors with enhanced properties. For example, in most industrial processes, Ni and $\mathrm{Sn}$ are typically electroplated on thick film conductors, which are used as the electrode termination of chip components, and in many cases, the thick-film conductors are soaked in acidic solutions during the electroplating process. ${ }^{16)-19)}$ In such process, acidic chemical durability is essential for thick-film conductors.

The purpose of this study is to investigate the influence of the addition of $\mathrm{MgO}$ powder to the alkali and alkalineearth borosilicate (AEB) glass paste on the acid durability and peel adhesion characteristics of Ag conductors formed on the $\mathrm{Al}_{2} \mathrm{O}_{3}$ substrate with the AEB glass paste. We examined the correlation between the acid corrosion behavior of the AEB glass thick-film and the peel adhesion characteristics in an acidic solution for the Ag conductors formed using the AEB glass pastes with/without the $\mathrm{MgO}$ powder addition.

\section{Experimental procedures}

\subsection{Preparation of glass frit for thick-film pastes}

$\mathrm{SiO}_{2}$ (Fujifilm Wako Pure Chemical Corp., $99.9 \%$ pure), $\mathrm{H}_{3} \mathrm{BO}_{3}$ (Sigma-Aldrich Corp., $\geq 99.5 \%$ pure), $\mathrm{Na}_{2} \mathrm{CO}_{3}$ (Sigma-Aldrich, $\geq 99.5 \%$ pure), $\mathrm{Al}(\mathrm{OH})_{3} \quad$ (Wako, $\geq 95.0 \%$ pure), $\mathrm{BaCO}_{3}$ (Sigma-Aldrich, $\geq 99.0 \%$ pure), $\mathrm{SrCO}_{3}$ (Sigma-Aldrich, $\geq 99.9 \%$ pure), ZnO (SigmaAldrich, $\geq 99.0 \%$ pure), $\mathrm{TiO}_{2}$ (Sigma-Aldrich, $\geq 99.0 \%$ pure), $\mathrm{Mg}(\mathrm{OH})_{2}$ (Sigma-Aldrich, $\geq 95.0 \%$ pure) and $\mathrm{SnO}_{2}$ (Sigma-Aldrich, 99.9\% pure) were used as starting materials of the AEB glass. The nominal composition (wt \%) of the synthesized AEB glass was as follows: $\mathrm{SiO}_{2} 20.5$, $\mathrm{B}_{2} \mathrm{O}_{3} 20.0, \mathrm{Na}_{2} \mathrm{O} 3.0, \mathrm{Al}_{2} \mathrm{O}_{3} 3.0, \mathrm{BaO} 19.0, \mathrm{SrO} 12.5, \mathrm{ZnO}$ 10.5, $\mathrm{TiO}_{2}$ 6.5, $\mathrm{MgO} 3.0$ and $\mathrm{SnO}_{2}$ 2.0. Here a small amount of $\mathrm{MgO}$ in glass is expected to improve water resistance and mechanical properties of the obtained AEB glass frit; the role of this addition differs from that of the addition of the $\mathrm{MgO}$ powder to the AEB glass paste, which will be described later. ${ }^{6,8), 20)} \mathrm{A}$ batch was weighed, mixed, and melted in a platinum crucible in an electrical furnace at $1300{ }^{\circ} \mathrm{C}$ for approximately $1.5 \mathrm{~h}$ to produce clear and homogeneous liquid. After the melted glass was evenly

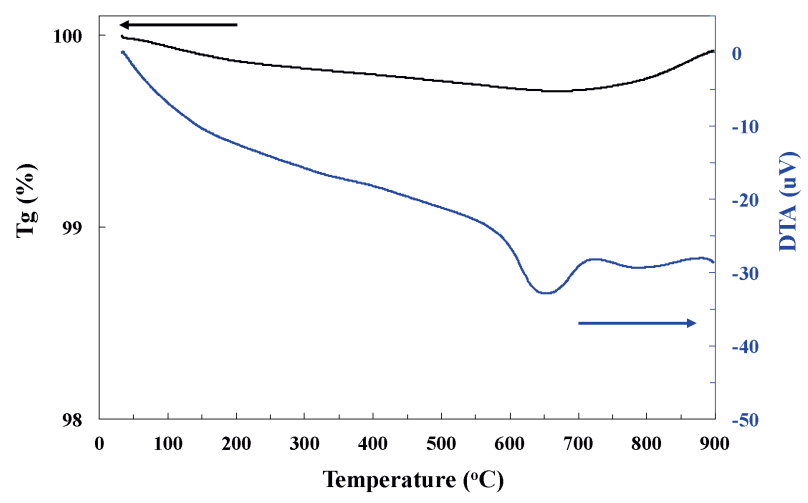

Fig. 1. TG/DTA pattern of the AEB glass frit heated in air.

Table 1. Composition of the thick-film pastes (wt \%)

\begin{tabular}{cccccc}
\hline Category & $\begin{array}{c}\text { Sample } \\
\text { name }\end{array}$ & $\begin{array}{c}\text { AEB } \\
\text { glass frit }\end{array}$ & $\begin{array}{c}\mathrm{MgO} \\
\text { powder }\end{array}$ & $\begin{array}{c}\mathrm{Ag} \\
\text { powder }\end{array}$ & $\begin{array}{c}\text { Organic } \\
\text { vehicle }\end{array}$ \\
\hline Glass pastes & GTF-1 & 70 & - & - & 30 \\
& GTF-2 & 65 & 5 & - & 30 \\
Ag conductor & ATF-1 & 7 & - & 60 & 33 \\
pastes & ATF-2 & 6.5 & 0.5 & 60 & 33 \\
\hline
\end{tabular}

distributed, that was immediately poured onto the roller quencher and then ball-milled in isopropanol to produce AEB glass frit (average particle size of $2 \mu \mathrm{m}$ ). Thermal behavior of the AEB glass frit was examined by a thermogravimetry-differential thermal analysis instrument (TG/DTA6300, SII Nano Technology, Inc.) at a heating rate of $40^{\circ} \mathrm{C} / \mathrm{min}$ in air. The glass transition temperature $\left(\mathrm{T}_{\mathrm{g}}\right)$ was approximately $570^{\circ} \mathrm{C}$ and the clear crystal peak was not observed by $850^{\circ} \mathrm{C}$, as shown in Fig. 1 .

\subsection{Preparation of the glass thick films and Ag conductors on $\mathrm{Al}_{2} \mathrm{O}_{3}$ substrates}

As shown in Table 1, two types of glass pastes and two types of Ag conductor pastes were prepared by mixing different ratios of the $\mathrm{AEB}$ glass frit, $\mathrm{MgO}$ powder (Konoshima Chemical Co., Ltd., $\geq 98 \%$ pure, average particle size of $2 \mu \mathrm{m}$ ), and $\mathrm{Ag}$ powder (average particle size of $2 \mu \mathrm{m})$ with an organic vehicle using a three-roll mill. The $\mathrm{MgO}$ powder was added to the two thick-film pastes and the ratio of the $\mathrm{MgO}$ powder to the AEB glass frit was fixed. The organic vehicle was composed of ethyl cellulose, terpineol and diethylene glycol dibutyl ether. The thick films were prepared by screen printing the thick-film pastes onto the dense sintered $\mathrm{Al}_{2} \mathrm{O}_{3}$ substrates (A476T, Kyocera Corp.). After the printing process, the samples were dried at $150{ }^{\circ} \mathrm{C}$ for $10 \mathrm{~min}$ to remove the volatile organic solvent. Next, the samples were heated to $850^{\circ} \mathrm{C}$ at the average rate of $75^{\circ} \mathrm{C} / \mathrm{min}$ under the atmosphere and fired at that temperature for $10 \mathrm{~min}$. The thicknesses and the calculated average roughness of the annealed thick films were measured by a surface texture measuring instrument (Surfcom480A, Tokyo Seimitsu Co., Ltd.). For these annealed thick films, the crystallization behavior and the characteristics of acidic corrosion and peel adhesion were examined. 


\subsection{Acid corrosion test of the thick films}

The AEB glass thick films and AEB-based Ag conductors on $\mathrm{Al}_{2} \mathrm{O}_{3}$ substrates were immersed in a $1 \mathrm{M} \mathrm{H}_{2} \mathrm{SO}_{4}$ aq. at 25,60 , or $80^{\circ} \mathrm{C}$ for $15,30,45$, and $60 \mathrm{~min}$ at each temperature. All samples were repeatedly washed with distilled water and then dried at room temperature overnight prior to the peel adhesion tests and characterization. The weights of the thick films before the corrosion test and the weight losses of the corroded thick films in acid solutions were measured by an electric analytical balance (AT200, Mettler-Toledo International, Inc.).

\subsection{Peel adhesion test of the Ag conductors}

The peel adhesion of the Ag conductors immersed in a $\mathrm{H}_{2} \mathrm{SO}_{4}$ aq. was examined by the following procedure. After polishing the surface of the AEB-based Ag conductors printed on an $\mathrm{Al}_{2} \mathrm{O}_{3}$ substrate, $\mathrm{Sn}$-covered copper wires were attached to $2 \mathrm{~mm} \times 2 \mathrm{~mm}$ pads by dipping for $10 \mathrm{~s}$ in a solder ( $\mathrm{Sn} 96.5 \mathrm{wt} \%, \mathrm{Ag} 3.0 \mathrm{wt} \%$, and $\mathrm{Cu} 0.5 \mathrm{wt} \%$ ) at $260^{\circ} \mathrm{C}$ using an Alpha 611 flux (Alpha Assembly Solutions, Inc.). The wires were pulled using a pull tester with a $90^{\circ}$ peel configuration, as illustrated in Fig. 2. The peel adhesion was measured using a pull tester (1605NHTP, Aiko Engineering Co., Ltd.). The remaining Ag conductors on $\mathrm{Al}_{2} \mathrm{O}_{3}$ substrates after the peel adhesion test were photographically observed with a microscope (BX51, Olympus Corp.).

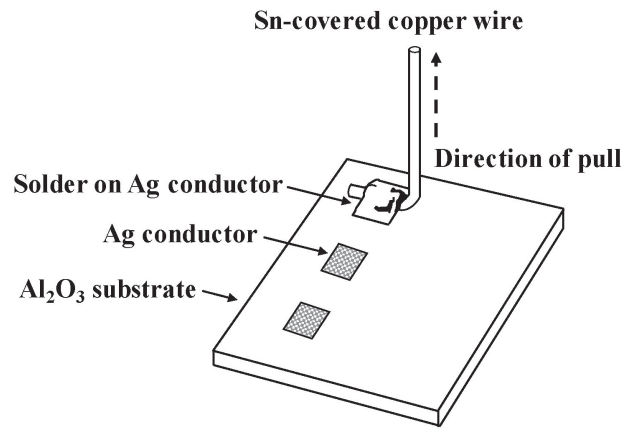

Fig. 2. Schematic depiction of the Ag conductor used for the peel adhesion test.

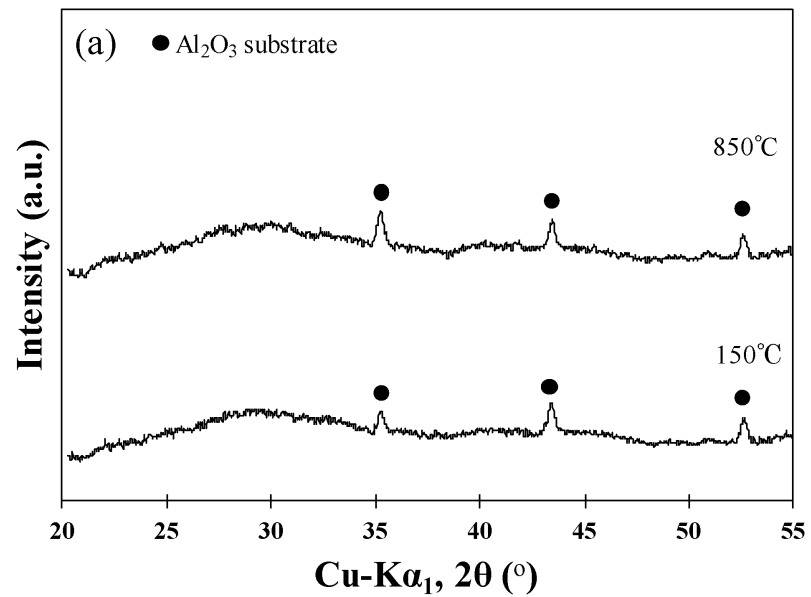

\subsection{Thick-film characterization}

Several instruments were simultaneously used to properly characterize the thick films. The crystalline phases before the corrosion test were identified by X-ray diffraction (XRD; D8, Bruker Corp.) with a monochromator employing $\mathrm{Cu}-\mathrm{K} \alpha_{1}$ radiation $[\lambda=1.5406 \AA(1 \AA=0.1$ $\mathrm{nm})]$. The surface morphology of the thick films before and after the corrosion test was observed with a scanning electron microscope (SEM; FlexSEM 1000, Hitachi HighTechnologies Corp.). The cross section of the thick films was observed using another SEM (Merlin, Carl ZEISS Microscopy $\mathrm{GmbH}$ ) and a scanning transmission electron microscope (STEM; JEM-F200, JEOL Ltd.).

\section{Results and discussion}

3.1 Effect of the MgO powder addition to glass pastes on the structure of glass during the annealing process

Figure 3 shows the XRD patterns of the AEB glass thick-film with (b)/without (a) the $\mathrm{MgO}$ powder on $\mathrm{Al}_{2} \mathrm{O}_{3}$ substrates after annealing at 150 and $850^{\circ} \mathrm{C}$. As shown in Fig. 3(a), the XRD patterns of the GTF-1 glass thick-film did not exhibit a crystalline diffraction peak except for the peaks attributed to the $\mathrm{Al}_{2} \mathrm{O}_{3}$ substrate (PDF card No. 711123). This indicates the amorphous state of the AEB glass annealed at the temperature as high as $850^{\circ} \mathrm{C}$. However, in Fig. 3(b), the peak assigned to $\mathrm{MgO}$ (200) plane at about $43^{\circ}$ (PDF card No. 4-0829) was observed in the XRD pattern of the GTF-2 glass thick-film annealed at $150{ }^{\circ} \mathrm{C}$. This observation indicates the absence of reaction between the added $\mathrm{MgO}$ powder and the AEB glass matrix at $150^{\circ} \mathrm{C}$. After annealing at $850^{\circ} \mathrm{C}$, the peak attributed to the $\mathrm{MgO}$ disappeared, and the peaks attributed to (Ba, $\mathrm{Sr}_{2} \mathrm{Al}_{2} \mathrm{Si}_{2} \mathrm{O}_{8}$ (BSAS) were observed, as shown in the upper pattern in Fig. 3(b). Although the diffraction peaks of the GTF-2 glass thick-film were close to those of $\mathrm{Ba}_{0.75} \mathrm{Sr}_{0.25} \mathrm{Al}_{2} \mathrm{Si}_{2} \mathrm{O}_{8}$ (PDF card No. 38-1451), additional experiments are required to determine the accurate ratio of $\mathrm{Ba}$ to $\mathrm{Sr}$ in the obtained BSAS. It is known that $\mathrm{BaAl}_{2} \mathrm{Si}_{2} \mathrm{O}_{8}$ (BAS) and $\mathrm{SrAl}_{2} \mathrm{Si}_{2} \mathrm{O}_{8}$ (SAS) form solid

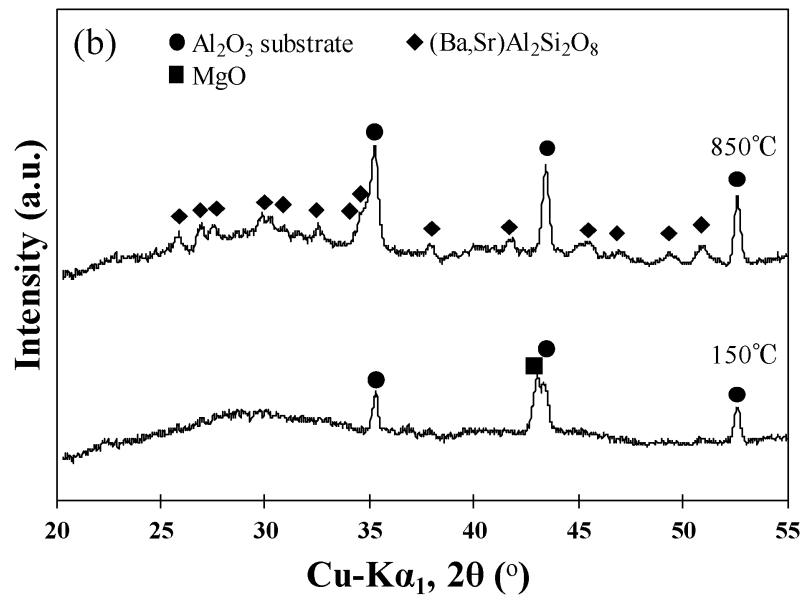

Fig. 3. XRD patterns of the glass thick films on $\mathrm{Al}_{2} \mathrm{O}_{3}$ substrates annealed at 150 and $850{ }^{\circ} \mathrm{C}$ : (a) GTF-1 and (b) GTF-2. 

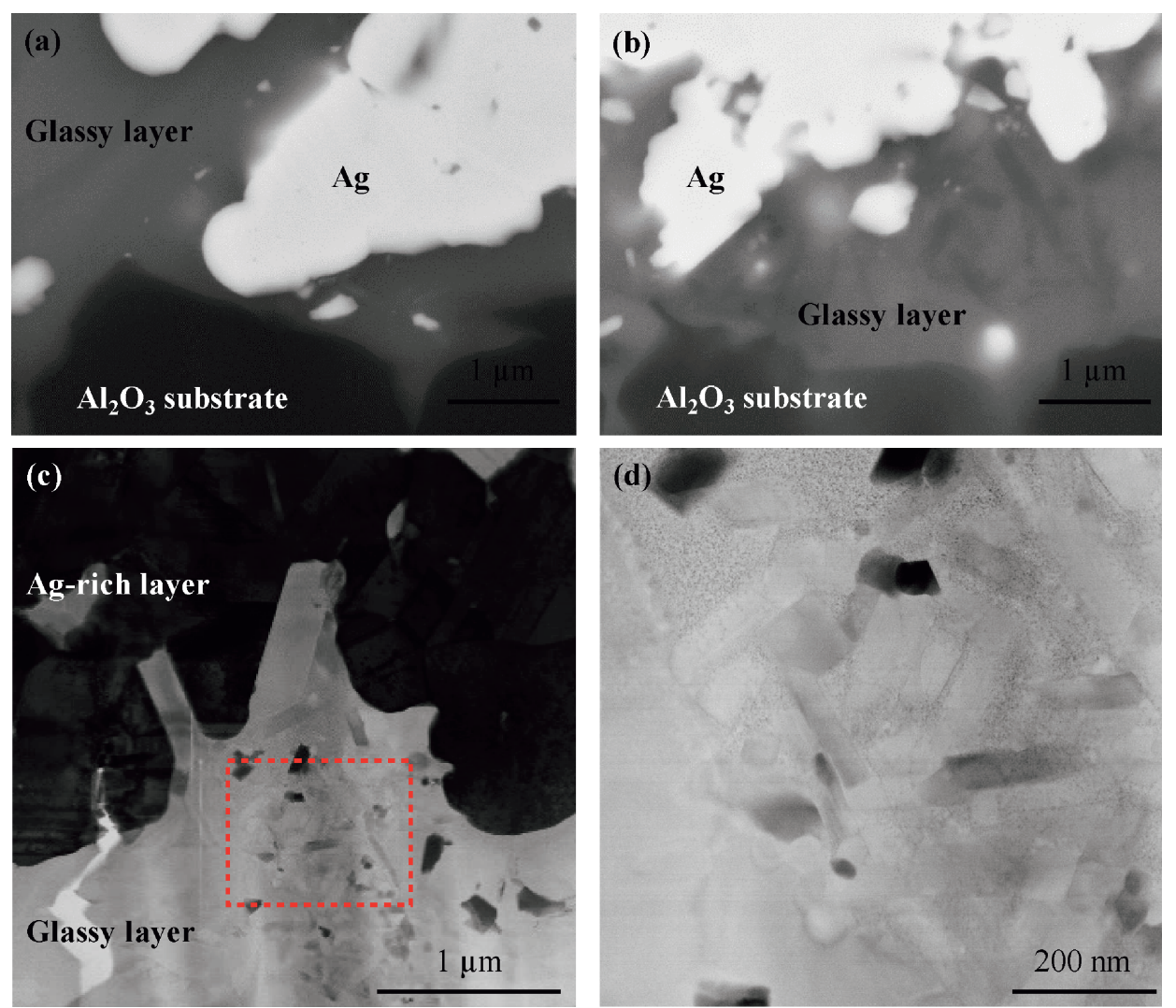

Fig. 4. SEM and STEM images of the cross section of the ATF-1 and ATF-2Ag conductors at $850^{\circ} \mathrm{C}$ : (a) SEM image of ATF-1, (b) SEM image of ATF-2, (c) BF-STEM image of ATF-2, and (d) BF-STEM image of the red dotted region in (c).

solutions in the entire composition range and the polymorphism exists. ${ }^{21)}$ These results suggest that the microcrystallization of the AEB glass was promoted by the reaction of the added $\mathrm{MgO}$ powder with the AEB glass frit. A further study on the composition-crystallization relationship is necessary to elucidate the detailed crystallization mechanism.

Figure 4 presents the SEM images of the cross section of the ATF-1 and ATF-2 Ag conductor [(a)-(b)], and the STEM images of the cross section of the ATF-2 thick-film with the $\mathrm{MgO}$ powder addition [(c)-(d)]. The different contrast areas were clearly observed in the glassy layer of the ATF-2 Ag conductor, whereas those were not observed in the ATF-1 Ag conductor, as shown in Figs. 4(b) and 4(a). Furthermore, as seen in the glassy region image Fig. 4(d) of the red dotted area of Fig. 4(c), rectangular micro-crystalline particles were observed at the different contrast areas of the ATF-2 Ag conductor. It is suggested that crystallization, promoted by the addition of $\mathrm{MgO}$ powder to the glass paste, happens in the Ag conductor of ATF-2, and Ag powder does not affect the microcrystallization. These results demonstrate that the small amount of $\mathrm{MgO}$ powder-added to the thick-film pastes promoted the crystallization of the AEB glass in the thickfilm. On the other hand, a further study is needed to reveal that the micro-crystals in the ATF-2 Ag conductor are the same as those in the GTF-2 glass thick-film.

\subsection{Acid durability of the thick films}

Figure 5 shows the corrosion weight loss of the GTF-1 glass thick-film (a) and GTF-2 glass thick-film (b) as a function of immersion time in a $\mathrm{H}_{2} \mathrm{SO}_{4}$ aq. The weight of the glass thick-film was approximately $26 \mathrm{mg}$ before the corrosion test, and the area was approximately $4.84 \mathrm{~cm}^{2}$. The average thickness was approximately $16 \mu \mathrm{m}$ and the calculated average roughness was approximately $0.8 \mu \mathrm{m}$. The weight loss of the GTF-1 glass thick-film without the addition of $\mathrm{MgO}$ powder increased monotonously with increasing immersion time up to $60 \mathrm{~min}$ at all temperatures. The weight loss of the GTF-2 glass thick-film with the added $\mathrm{MgO}$ powder increased by approximate $15 \mathrm{~min}$ of immersion at all temperatures, and then the weight loss remained approximately constant after $45 \mathrm{~min}$ of immersion at $25^{\circ} \mathrm{C}$ and after $30 \mathrm{~min}$ of immersion at 60 and $80^{\circ} \mathrm{C}$ respectively. The weight loss rate of the GTF- 1 and GTF-2 glass thick-film was accelerated at high temperature. It is known that elution of alkali and $\mathrm{B}_{2} \mathrm{O}_{3}$ in glass is accelerated at high temperature. ${ }^{22)}$ It is noted that the GTF-2 glass thick-film with the added $\mathrm{MgO}$ powder exhibits approximately half the weight loss of the GTF-1 glass thick-film without the $\mathrm{MgO}$ powder for the 60-min immersion. This observation indicates an improvement in the acid durability of the glass thick-film owing to the addition of the $\mathrm{MgO}$ powder to the glass paste. Although the AEB glass comprised a small amount of $\mathrm{MgO}$, the acid 
durability of the AEB glass thick-film was weak without the addition of $\mathrm{MgO}$ powder. A further study is necessary to clarify the effect and detailed mechanism of $\mathrm{MgO}$ addition in glass and glass thick-film on an improvement in the acid durability.

Figure 6 presents the SEM images of the GTF-1 glass thick-film [(a)-(c)] and GTF-2 glass thick-film [(d)-(f)] before and after the corrosion test at $25^{\circ} \mathrm{C}$. Both GTF-1 and GTF-2 glass thick-film had smooth surface before the corrosion test as shown in Figs. 6(a) and 6(d). However, the cracks were observed after the GTF-1 glass thick-film
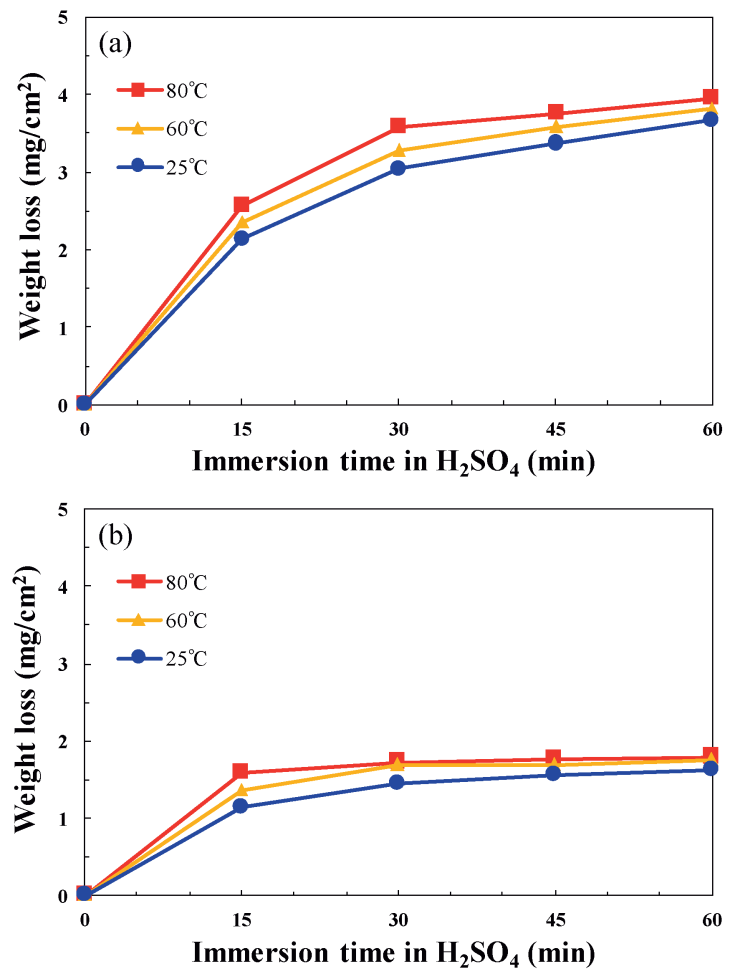

Fig. 5. Weight loss of the glass thick films on $\mathrm{Al}_{2} \mathrm{O}_{3}$ substrates corroded in a $1 \mathrm{M} \mathrm{H}_{2} \mathrm{SO}_{4}$ solution: (a) GTF-1 and (b) GTF-2. was immersed in a $\mathrm{H}_{2} \mathrm{SO}_{4}$ aq. for $15 \mathrm{~min}$, as seen in Fig. 6(b). The cracks became bigger, and their number increased during the immersion, as shown in Fig. 6(c). On the basis of previous studies, ${ }^{9), 11)}$ it is possible that three reactions occur mainly on the glassy surface under acidic solutions: 1) ion-exchange reactions in which modifier cations are replaced by $\left.\mathrm{H}^{+}\left(\mathrm{H}_{3} \mathrm{O}^{+}\right), 2\right)$ hydration in which water enters the glass, and 3 ) hydrolysis in which water reacts with the metal-oxygen bond in the glass. These reactions occur quickly, and then fast shrinkage may happen in the GTF-1 glass thick-film. The magnified SEM image of the GTF-1 glass thick-film after immersed in a $\mathrm{H}_{2} \mathrm{SO}_{4}$ aq. for $15 \mathrm{~min}$ is shown in the inset of Fig. 6(b). In the image, the deformation was clearly observed on the surface. On the other hand, the cracks were not observed on the surface of the GTF-2 glass thick-film after immersed in a $\mathrm{H}_{2} \mathrm{SO}_{4}$ aq., as seen in Figs. 6(e) and 6(f).

As shown in Fig. 3(b), the precipitation of the BSAS crystals occurred in the GTF-2 glass thick-film annealed at $850^{\circ} \mathrm{C}$. This phenomenon appears to be involved in the improvement of the acid resistance of the AEB glass thickfilm. The micro-crystallization in the AEB glass matrix may induce the compositional change of the glass matrix, which results in the observed acid durability enhancement of the glass matrix. Further experiments are necessary to clarify the chemical mechanism of the improved acid durability.

The print pattern of the Ag conductors was different as that of the glass thick films. The weight of the Ag conductor was approximately $3 \mathrm{mg}$ before the corrosion test, and the area was approximately $0.36 \mathrm{~cm}^{2}$. The average thickness was approximately $10 \mu \mathrm{m}$, and the calculated average roughness was approximately $0.7 \mu \mathrm{m}$. Since it was difficult to measure the weight loss of the ATF-1 and ATF-2 Ag conductor as a function of immersion time in $\mathrm{a}_{2} \mathrm{SO}_{4}$ aq. accurately, SEM analysis was performed to observe the corrosion behavior of the Ag conductor. Figure 7 shows the SEM images of the cross section of the ATF-1 and
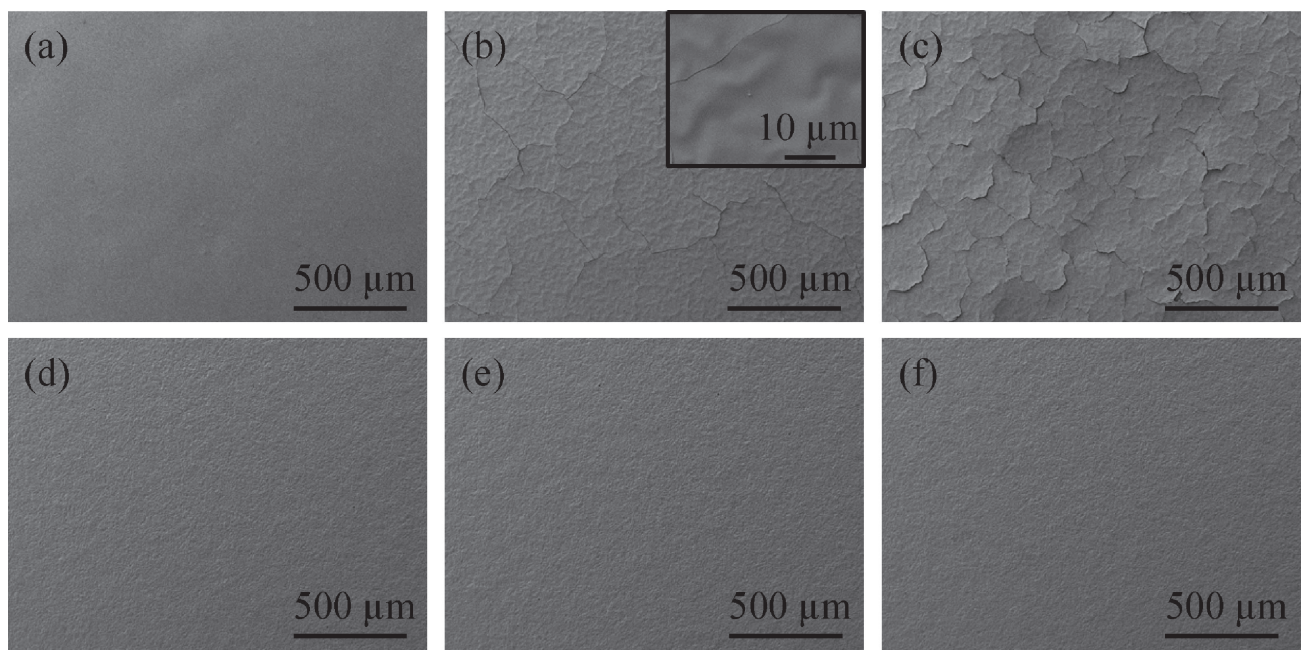

Fig. 6. SEM images of the surface of the glass thick films immersed for different periods of time in a $1 \mathrm{M}$ $\mathrm{H}_{2} \mathrm{SO}_{4}$ solution at $25^{\circ} \mathrm{C}$ : (a) GTF-1 for 0 min, (b) GTF-1 for $15 \mathrm{~min}$, (c) GTF-1 for $60 \mathrm{~min}$, (d) GTF-2 for 0 min, (e) GTF-2 for $15 \mathrm{~min}$, and (f) GTF-2 for $60 \mathrm{~min}$. 


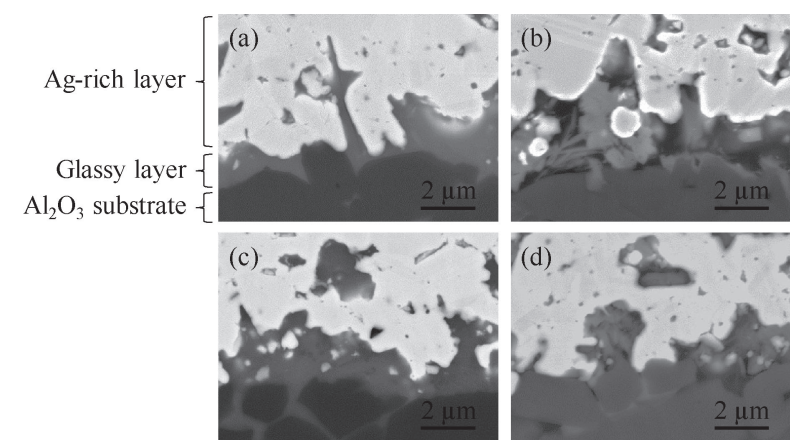

Fig. 7. SEM images of the cross section of the $\mathrm{Ag}$ conductors immersed for different periods of time in a $1 \mathrm{M} \mathrm{H}_{2} \mathrm{SO}_{4}$ solution at $25^{\circ} \mathrm{C}$ : (a) ATF-1 for $0 \mathrm{~min}$, (b) ATF-1 for $60 \mathrm{~min}$, (c) ATF-2 for $0 \mathrm{~min}$, and (d) ATF-2 for $60 \mathrm{~min}$.

ATF-2 Ag conductor before and after immersion in a $\mathrm{H}_{2} \mathrm{SO}_{4}$ aq. for approximate $60 \mathrm{~min}$. As shown in Figs. 7(a) and 7(c), a glassy layer was observed between the Ag-rich layer and $\mathrm{Al}_{2} \mathrm{O}_{3}$ substrates before the corrosion test, and glass fingers extend to the Ag-rich layer throughout the structure. This observation means that the glass-based bonding is formed in the ATF-1 and ATF-2 Ag conductor. It is known that a glass bonded thick-film conductor typically forms a metal-rich upper layer and a glass-rich lower layer. ${ }^{1)}$ As shown in Figs. 7(b) and 7(d), after immersion in $\mathrm{H}_{2} \mathrm{SO}_{4}$ aq., voids with low contrast appeared in the glassy layer, and large voids were observed in the ATF-1 $\mathrm{Ag}$ conductor in comparison to the ATF-2 Ag conductor. This observation indicates that the ATF-1 Ag conductor without the added $\mathrm{MgO}$ powder exhibited a more corroded glassy layer in comparison to the ATF-2 Ag conductor with the $\mathrm{MgO}$ powder addition. The $\mathrm{H}_{2} \mathrm{SO}_{4}$ aq. appears to penetrate to the Ag conductors and preferentially erode the glassy layer.

\subsection{Peel adhesion characteristics of the $\mathrm{Ag}$ conductors in an acidic solution}

Figure 8 illustrates the peel adhesion of the Ag conductors on $\mathrm{Al}_{2} \mathrm{O}_{3}$ substrates after immersion in a $\mathrm{H}_{2} \mathrm{SO}_{4}$ aq. for different periods of time. It is clear that the peel adhesion of the ATF-1 Ag conductor continued to decline with increasing immersion time, and it decreased to less than $1 \mathrm{~N}$ after 60 -min immersion. However, the degree of the adhesion deterioration of the ATF-2 Ag conductors with the added $\mathrm{MgO}$ powder was small in comparison to the ATF-1 Ag conductor. Because the obtained adhesion greatly depends on the weakest point in the soldered Ag conductors, the breaking location needs to be taken into account when elucidating the peel adhesion behavior.

Figure 9 shows the photographs of the remaining Ag conductors on $\mathrm{Al}_{2} \mathrm{O}_{3}$ substrates after the peel adhesion test. The failure mode of the ATF-1 and ATF-2 Ag conductor was not an interface failure between the thick-film conductor and $\mathrm{Al}_{2} \mathrm{O}_{3}$ substrate but a cohesive failure (i.e., failure in the bulk of the adhesive layer) before immersion in a $\mathrm{H}_{2} \mathrm{SO}_{4}$ aq., as shown in Figs. 9(a) and 9(d). However, the area of the remaining $\mathrm{Ag}$ conductors on $\mathrm{Al}_{2} \mathrm{O}_{3}$ substrates

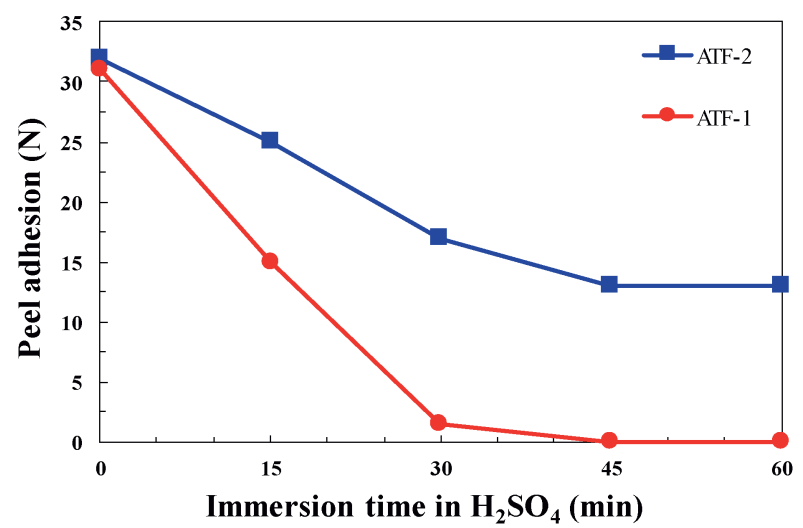

Fig. 8. Peel adhesion of the $\mathrm{Ag}$ conductors on $\mathrm{Al}_{2} \mathrm{O}_{3}$ substrates after immersion in a $1 \mathrm{M} \mathrm{H}_{2} \mathrm{SO}_{4}$ solution for different periods of time at $25^{\circ} \mathrm{C}$.
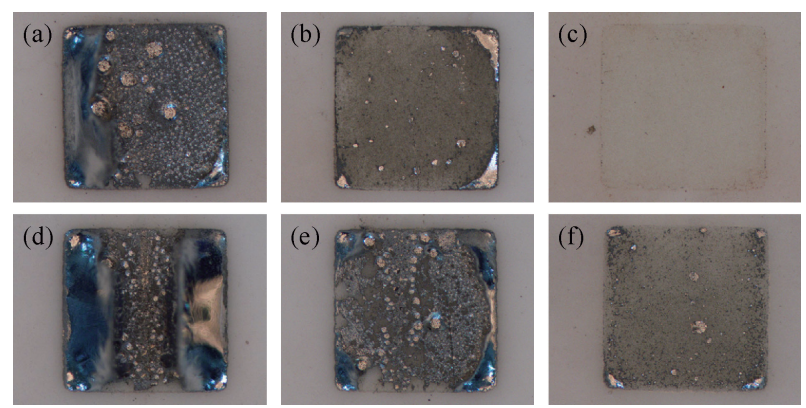

Fig. 9. Photographs of the peel adhesion-tested Ag conductors after immersed for different periods of time in a $1 \mathrm{M} \mathrm{H}_{2} \mathrm{SO}_{4}$ solution at $25^{\circ} \mathrm{C}$ : (a) ATF-1 for $0 \mathrm{~min}$, (b) ATF-1 for $15 \mathrm{~min}$, (c) ATF-1 for $60 \mathrm{~min}$, (d) ATF-2 for $0 \mathrm{~min}$, (e) ATF-2 for $15 \mathrm{~min}$, and (f) ATF-2 for $60 \mathrm{~min}$.

after acid immersion was found to be reduced with increasing immersion time, as seen in Figs. 9(b), 9(c), 9(e), and 9(f). This observation indicates that the failure mode changed to delamination between the thick-film and $\mathrm{Al}_{2} \mathrm{O}_{3}$ substrate. The observed change in abovementioned failure mode after acidic immersion was faster in the ATF-1 Ag conductor compared with the ATF-2 Ag conductor. These results suggest that the peel adhesion characteristics of the $\mathrm{Ag}$ conductors correspond to the acidic corrosion behavior of the glassy layer in a thick-film.

\section{Conclusions}

This study focused on investigating the influence of the addition of $\mathrm{MgO}$ powder to the AEB glass paste on the acid durability and peel adhesion characteristics of the $\mathrm{Ag}$ conductors formed on the $\mathrm{Al}_{2} \mathrm{O}_{3}$ substrate with the glass paste. It was observed that the addition of the small amount of the $\mathrm{MgO}$ powder to the glass paste promoted the precipitation of BSAS crystals in the glass thick-film during the annealing process at $850^{\circ} \mathrm{C}$. Improved acid durability was observed for the micro-crystalized glass thick-film with the added $\mathrm{MgO}$ powder on the basis of the weight loss characterization after immersion in a $1 \mathrm{M}$ $\mathrm{H}_{2} \mathrm{SO}_{4}$ aq. The STEM images showed the existence of micro-crystals in the glassy layer of the Ag conductors 
formed with the $\mathrm{MgO}$ powder-added AEB glass paste. This observation suggests that micro-crystallization, promoted by the addition of $\mathrm{MgO}$ powder to the glass paste, occurred in the Ag conductors. On the other hand, a further study is needed to reveal that the precipitated microcrystals in the Ag conductor are the same as those in the glass thick-film. The Ag conductors with the added $\mathrm{MgO}$ powder exhibited small corrosion behavior of the glassy layer (on the basis of the SEM images), small deterioration of peel adhesion in acidic solutions, and slow change of the failure mode in comparison to the $\mathrm{Ag}$ conductor formed using the glass paste without the $\mathrm{MgO}$ powder addition. These results suggest that the correlation between the improved acid durability and peel adhesion characteristics of the $\mathrm{Ag}$ conductor formed with the addition of $\mathrm{MgO}$ powder to the glass paste was related to the microcrystallization of the glass induced by the addition of $\mathrm{MgO}$ powder to the thick-film pastes during the annealing process at $850^{\circ} \mathrm{C}$.

Acknowledgement The authors would like to thank all members of DuPont Electronics Center for helpful discussions.

\section{References}

1) J. R. Larry, R. M. Rosenberg and R. O. Uhler, IEEE T. Compon. Hybr., 3, 211-225 (1980).

2) M. V. Coleman and G. E. Gurnett, Electrocomp. Sci. Tech., 5, 55-59 (1978).

3) B. E. Taylor, J. J. Felten, S. J. Horowitz, J. R. Larry and R. M. Rosenberg, Electrocomp. Sci. Tech., 9, 67-85 (1981).

4) J. Savage, "Handbook of thick film technology", Ed. by P. J. Holmes and R. G. Loasby, Electrochemical publications Ltd., Scotland (1976) pp. 97-113.

5) R. Terai, Mater. Integr., 17, 51-55 (2004).
6) R. Terai, Mater. Integr., 17, 55-61 (2004).

7) Y. Kasai, New Glass, 21, 36-41 (2006).

8) M. Tanaka, T. Uwabe, Y. Ito, D. Kojima and J. Ono, Bulletin of TIRI, 50-53, (2006).

9) B. C. Bunker, J. Non-Cryst. Solids, 179, 300-308 (1994).

10) F. Yanagisawa, Min. Geol., 40, 353-362 (1990).

11) H. A. Elbatal, M. A. Azooz, E. A. Saad, F. M. EzzELDin and M. S. Amin, Silicon, 10, 1139-1149 (2018).

12) M. Tashiro, J. Crystallogr. Soc. Jpn., 8, 147-156 (1966).

13) M. Tashiro, S. Sakka and T. Yamamoto, J. Ceram. Assoc. Jpn., 71, 152-157 (1963).

14) P. F. Becher and W. L. Newell, J. Mater. Sci., 12, 90-96 (1977).

15) P. F. Becher and J. S. Murday, J. Mater. Sci., 12, 10881094 (1977).

16) T. Nakada, Y. Kaneda, K. Fukui, N. Watanabe, A. Hashimoto and I. Koiwa, J. Jpn. Inst. Electron. Packag., 16, 66-69 (2013).

17) K. Oyamada and K. Akiyama, J. Surf. Finish. Soc. Jpn., 58, 637-640 (2007).

18) K. Tashiro and M. Saito, "Mekki Taizen", Ed. by Kantogakuin university, The Nikkan Kogyo Shimbun Ltd., Japan (2018) pp. 183-197, 228-243.

19) Y. Tsujimoto, H. Ikebe, T. Kuroda, T. Murakami, T. Nishida, K. Saeki, T. Kajikawa, H. Maruoka, N. Sugiura, S. Yamamura, H. Yamamoto, T. Tamai, M. Sumiyoshi, T. Arakawa and D. Matsui, "Surface Mount Technology", Ed. by T. Masuyama and T. Honda, Kogyo Chosakai Publishing Co., Ltd., Japan (1986) pp. 27-155.

20) G. H. Koenderink, R. H. Brzesowsky and A. R. Balkenende, J. Non-Cryst. Solids, 262, 80-98 (2000).

21) N. P. Bansal, J. Mater. Sci., 33, 4711-4715 (1998).

22) N. Takusagawa and H. Kawamura, Inorg. Mater., 4, 287-294 (1997). 